Research Article

\title{
Auditory brainstem response for Sri Lankan children under 5 years of age: Normativedata
}

Ileperuma $\mathrm{LD}^{1}$, Weerasinghe $\mathrm{VS}^{2}$, Wickremasinghe $\mathrm{AR}^{3}$

${ }^{1-}$ Department of Disability Studies, Faculty of Medicine, University of Kelaniya, Sri Lanka.

2- Department of Physiology, Faculty of Medicine, University of Peradeniya, Sri Lanka.

3- Department of Public Health, Faculty of Medicine, University of Kelaniya, Sri Lanka.

\begin{abstract}
For years Sri Lankan Audiologists resorted to western norms in the interpretation of Auditory Brainstem Response (ABR) in the absence of national standards. The study focused on establishing normative data on ABR for Sri Lankan children below 5 years.

ABR was performed on 258 healthy children between 6 weeks and 5 years of age to gather data on absolute latencies and inter-peak latencies.All inter-aural differences were within $0.2-0.4 \mathrm{~ms}$. The mean inter-aural difference for the study sample was significantly small $(-0.0204 \mathrm{~ms}$ to $0.0286 \mathrm{~ms})$. Mean values of absolute latencies for waves I, III, V for the 6-week age group at 30dBnHL were $3.33 \mathrm{~ms}, 5.91 \mathrm{~ms}$ and $8.27 \mathrm{~ms}$ respectively. Mean values of inter-peak latencies of wave I-III, III-V, I-V were $2.08 \mathrm{~ms}, 2.36 \mathrm{~ms}$ and $4.76 \mathrm{~ms}$ respectively for the 6 -week age group at $30 \mathrm{dBnHL}$.

The normative ABR data obtained in this study may be used across audiology clinics in Sri Lanka as a baseline measurement to diagnose hearing loss among children from infancy to 5 years of age when children are tested in their natural sleep and insert earphones are used. The mean value plus 2 standard deviations for each ABR measure may be used as the upper limit cutoff values. Hence this study helps eliminate misdiagnosis and under-diagnosis of hearing loss in children.
\end{abstract}

Keywords :ABR, Children, normative data

Copyright: (C) 2022 Ileperuma LDet al.

This is an open access article distributed under the Creative Commons Attribution License (CC BY 4.0)

(c) () as long as they credit the original author for the creation.

Funding: None

Competing interest: None

Correspondence: MsDinukshilleperuma (dinukshi13@kln.ac.lk)

Published Date: $31^{\text {st }}$ December 2021 


\section{Introduction}

Auditory Brainstem Response has been recognized as a valuable diagnostic tool in identifying hearing disorders in the paediatric population. ABR evaluation is useful for early detection of hearing impairment in high-risk infants, so that rehabilitation measures can be initiated as early as possible.

It is difficult to identify abnormal ABR without the knowledge of normative ABR data. Hence, establishing normative data in terms absolute latencies, inter-peak latencies, peak amplitudes, amplitude ratios, inter-peak latency ratios and latency-intensity function curves are advantageous.As ABR latencies are prolonged in infants and children, relative to that of adults ${ }^{1}$, the use of adult normative values of ABR in the evaluation of infants and children may result in errors and may label a child who is in no way hearing impaired as having a hearing loss. This creates the necessity to establish a separate set of normative data for the paediatric population.

Khatoon et $a l^{2}$ measured ABR recordings from 40 full term infants, from 1-month to 5-year old children with normal hearing and neuropsychological development and from 20 adults 18-25 years of age. They observed that the wave I absolute latency reached adult values by 3 years of age whereas wave $\mathrm{V}$ absolute latency reached adult values by 5 years of age. It was noted that in general, the absolute and inter-peak latencies reached adult values by 18-36 months of age. Inter-peak latencies decreased from 1 month to 5 years. The amplitudes of all waves increased with age, the largest changes occurring during early infancy. The adult values of wave I amplitude was reached at 6 months and of wave $\mathrm{V}$ at 2 years of age.

Issa \& Ross ${ }^{3}$ developed a new set of normative data on ABR for young subjects which varied greatly from adult ABR normative data. They measured ABR responses of fetuses of 32 weeks of gestation to adults more than 25 years of age.

Gorga et $\mathrm{al}^{4}$ collected ABR data from 535 children between 3 months and 3 years of age. It was concluded that wave V latency and inter-peak latencies decreased as age increased from 3 months to 1824 months and if ABR latencies are to be used in the assessment of children, age appropriate norms should be employed.

National standards describing normative ABR values for children have not been established in Sri Lanka, even though click and tone-burst stimuli have been used in ABR evaluations for many years. This could lead to the danger of misdiagnosis or under-diagnosis of hearing impairment. Currently, Western standards are used in most audiology clinics in Sri Lanka. Age, gender, core temperature, stimulus rate, stimulus polarity, electrode impedance, and electrode montage affect ABR. Even though the impact of the variables affecting ABR results is small and of possibly of little clinical significance, the collective effects of several instrument and procedural variables may produce clinically important differences. It is possible that these values can change for a Sri Lankan paediatric population, based on certain variables.

The purpose of this study was to derive normative data for absolute latencies of waves I, III and V and inter-peak latencies of I-III, III-V and I-V for six different age groups under 5 years of age. 


\section{Method}

\section{Subjects}

258 neurologically and otologically intact Sri Lankan children under 5 years of age were randomly selected from the Gampaha district. Infants and children were identified through records maintained by Public Health Midwives (PHMs) of this district. The study population was divided into 6 groups: 6 weeks, 3 months, 6 months, 1 year, 2 years and 3-5 years ${ }^{5}$ (Table 1).

\begin{tabular}{|l|l|l|l|l|}
\hline Group & Age & Males & Females & Total subjects \\
\hline 1 & 6 weeks & 21 & 22 & 43 \\
\hline 2 & 3 months & 25 & 18 & 43 \\
\hline 3 & 6 months & 18 & 25 & 43 \\
\hline 4 & 1 year & 21 & 22 & 43 \\
\hline 5 & 2 years & 19 & 24 & 43 \\
\hline 6 & $3-5$ years & 19 & 24 & 43 \\
\hline Total & & 123 & 135 & 258 \\
\hline
\end{tabular}

Table 1: Age and gender distribution of the subjects

Basic, socio-demographic, prenatal, perinatal, post-natal, developmental and relevant clinical data were collected from the mother/caregiver using an interviewer-administered questionnaire. All children were then subjected to the Denver Developmental Screening Test $\left(2^{\text {nd }}\right.$ edition$)$. Otoscopic examination, tympanometry and Oto Acoustic Emissions were performed on children was performed prior to ABR testing. Children who had outer and/or middle ear pathology were excluded from the study. Such children were referred for ENT management. Approval and clearance was obtained from the Ethics committee of the Faculty of Medicine, University of Kelaniya. Permission to conduct the study was obtained from the Regional Director Health Services of the Gampaha district. Children were recruited after obtaining informed written consent from the parents/guardian.

\section{Stimuli and recording technique}

A Biologic Navigator Pro AEP system was used for ABR data collection. All children were tested under natural sleep. Standard disc electrodes were attached to both mastoids and high forehead (single channel recording-the International 10-20 system for electrode placement). The electrode impedance was kept under $3 \mathrm{k} \Omega$ between all electrodes. $100 \mu \mathrm{s}$ rarefaction and condensation click stimuli at the rate of 13.1 $\mathrm{Hz}$ were introduced to each ear via ER-3A insert earphones starting at an intensity level of $70 \mathrm{dBnHL}$. Each test run comprised of 2000 sweeps. The low pass filter was set at $3000 \mathrm{~Hz}$ and the high pass filter was set at $30 \mathrm{~Hz}$. Each waveform was replicated once to determine reliability. The ABR threshold was obtained by decreasing the intensity level by $10 \mathrm{~dB}$ steps until a clearly identifiable peak $\mathrm{V}$ could be observed. Each ear was tested separately in this manner. Peaks I, III, V of the waves were labeled on each waveform. The absolute latencies for peaks I, III and V and inter-peak latencies of I-III and I-V were recorded. All audiological tests were carried out in a sound treated room.

\section{Data analysis}

Absolute latencies of waves I, III, V and inter-peak latencies of I-III, III-V and I-V were the ABR measurements which were analysed. Waves were visually identified and labeled. Absolute latency was measured from stimulus onset to the positive peak of each wave. The SPSS 16.0 software was used for statistical analysis. Means and standard deviations were calculated for absolute latencies, inter-peak latencies and inter-aural differences for each age group. The paired $t$ test was used in inter-aural symmetry while for gender differences thestudent's t testwas employed. The one sample KolmogorovSmirnov test was used to identify distributions that differ significantly from normal. 


\title{
Results
}

\section{Inter-aural symmetry}

All inter-aural differences lie within 0.2-0.4 ms. The mean inter-aural differences for all parameters were significantly small, ranging from $-0.0204 \mathrm{~ms}$ to $0.0286 \mathrm{~ms}$. There was no statistically significant difference in inter-aural differences between the right and left ears ( $p>0.05)$. Hence only the right ear values were considered for absolute and inter-peak latencies.

\begin{abstract}
Absolute latencies
Absolute latency values of waves I, III and V increased as the intensity decreased within a given age group. Wave I, III and V absolute latency decreased as a function of age (Table 2).

The mean wave III latencies and standard deviations as a function of age for different intensity levels were obtained. The one sample Kolmogorov-Smirnov test for normality of wave III and wave V latency were significant $(\mathrm{p}<0.05)$ for $40 \mathrm{dBnHL}$ and $70 \mathrm{dBnHL}$ in the 6-week age group and for $30 \mathrm{dBnHL}$ in the 2 -year age group respectively while in all other age groups the latencies were normally distributed. There was no observable relationship between the standard deviation and intensity levels.
\end{abstract}

\section{Inter-peak latencies}

As observed in the absolute latencies, an orderly decrease in the IPLs was observed with increasing age (Table 2). The standard deviations for I-III IPL appear to be independent of age. The one sample Kolmogorov-Smirnov test for normality of the I-III and I-III IPL were significant for $70 \mathrm{dBnHL}$ in the 1year age group and for $40 \mathrm{dBnHL}$ in the 6-week age group respectively while in all other age groups the IPLs were normally distributed. The one sample Kolmogorov-Smirnov test for normality of the I-V IPL in all age groups was normally distributed.

\begin{tabular}{|l|l|l|l|l|l|r|}
\hline $\begin{array}{l}\text { ABR } \\
\text { measure }\end{array}$ & 6 weeks & 3 months & 6 months & 1 year & 2 years & $3-5$ years \\
\hline Wave I & $1.96 \pm 0.38$ & $1.9 \pm 0.52$ & $1.87 \pm 0.52$ & $1.88 \pm 0.44$ & $1.84 \pm 0.32$ & $1.79 \pm 0.42$ \\
\hline Wave III & $4.7 \pm 0.7$ & $4.58 \pm 0.56$ & $4.47 \pm 0.36$ & $4.33 \pm 0.62$ & $4.27 \pm 0.68$ & $4.23 \pm 0.5$ \\
\hline Wave V & $6.9 \pm 0.43$ & $6.66 \pm 0.56$ & $6.38 \pm 0.5$ & $6.26 \pm 0.76$ & $6.11 \pm 0.84$ & $6.04 \pm 0.76$ \\
\hline I-III IPL & $2.77 \pm 0.7$ & $2.64 \pm 0.66$ & $2.59 \pm 0.5$ & $2.46 \pm 0.68$ & $2.39 \pm 0.74$ & $2.58 \pm 0.56$ \\
\hline III-V IPL & $2.71 \pm 0.6$ & $2.05 \pm 0.72$ & $1.91 \pm 0.44$ & $1.93 \pm 0.28$ & $1.81 \pm 1$ & $1.72 \pm 1.04$ \\
\hline I-V IPL & $4.95 \pm 0.56$ & $4.66 \pm 0.84$ & $4.56 \pm 0.44$ & $4.42 \pm 0.76$ & $4.21 \pm 0.84$ & $4.24 \pm 0.76$ \\
\hline
\end{tabular}

Table 2: Mean absolute latencies and inter-peak latencies across age groups at 70dBnHL

\section{Discussion}

\section{ABR threshold}

This study shows that wave $\mathrm{V}$ is present from $70 \mathrm{~dB}$ to $30 \mathrm{~dB}$ bilaterally for all age groups. Wave I was present only up to $50 \mathrm{dBnHL}$ and wave III was present only up to $40 \mathrm{dBnHL}$. This shows that wave $\mathrm{V}$ is the most robust wave which can be considered as a marker for hearing in ABR studies. This has been previously reported in literature ${ }^{6,7,8}$.

In this study, results of the Kolmogorov-Smirnov test (K-S test) have indicated that the absolute latencies and IPLs at each $\mathrm{dB}$ level for each age group is normally distributed. Therefore, it is assumed that the means and SDs of the parameters measured in this study provide accurate description of each distribution. 


\section{Comparison of absolute latencies and IPL with previous studies}

\section{$\underline{6 \text { weeks }}$}

Six-week old Sri Lankan children had a significant delay of $0.31 \mathrm{~ms}$ in the mean wave I latency as compared to children from the UCLA Medical Center well-born nursery, studied by Zimmerman et al ${ }^{9}$ (Table 3). The mean wave III latency and wave V latency of Sri Lankan children were delayed by $0.34 \mathrm{~ms}$ and $0.45 \mathrm{~ms}$ respectively when compared to Zimmerman et al $^{9}$ (Table 5.1). Delays in Sri Lankan children were also seen in wave I-III IPL, wave III-V IPL and wave I-V IPL by $0.16 \mathrm{~ms}, 64 \mathrm{~ms}$ and $0.25 \mathrm{~ms}$ respectively compared to data of Zimmerman et $a l^{9}$ (Table 3).Mean absolute latency values of wave I, III and $\mathrm{V}$ and inter-peak latencies of wave III-V and I-V for the 6-week old infants were significantly different $(\mathrm{p}<0.05)$ from those reported by Zimmerman et al ${ }^{9}$ (Table 3$)$.

\begin{tabular}{|c|c|c|c|c|c|c|c|c|}
\hline \multirow{2}{*}{$\begin{array}{l}\text { ABR } \\
\text { measure }\end{array}$} & \multicolumn{3}{|c|}{ Ileperuma et al. (2015) } & \multicolumn{3}{|c|}{ Zimmerman et al. (1987) } & \multirow[t]{2}{*}{ t value } & \multirow[t]{2}{*}{$\mathrm{p}$ value } \\
\hline & $\mathrm{n}$ & $\begin{array}{c}\text { Mean } \\
(\mathrm{ms})\end{array}$ & SD & $\mathrm{N}$ & $\begin{array}{c}\text { Mean } \\
(\mathrm{ms})\end{array}$ & SD & & \\
\hline $\begin{array}{l}\text { Wave I } \\
\text { absolute } \\
\text { latency }\end{array}$ & 42 & 1.96 & 0.19 & 19 & 1.75 & 0.17 & 4.3 & 0.0001 \\
\hline $\begin{array}{l}\text { Wave III } \\
\text { absolute } \\
\text { latency }\end{array}$ & 43 & 4.7 & 0.35 & 19 & 4.36 & 0.27 & 4.15 & 0.0001 \\
\hline $\begin{array}{l}\text { Wave V } \\
\text { absolute } \\
\text { latency }\end{array}$ & 43 & 6.9 & 0.19 & 19 & 6.45 & 0.23 & 7.47 & 0.0001 \\
\hline $\begin{array}{l}\text { Wave } \\
\text { I-III IPL }\end{array}$ & 42 & 2.77 & 0.35 & 19 & 2.61 & 0.35 & 1.65 & 0.107 \\
\hline $\begin{array}{l}\text { Wave III- } \\
\text { V IPL }\end{array}$ & 43 & 2.71 & 0.3 & 19 & 2.08 & 0.3 & 7.62 & 0.0001 \\
\hline $\begin{array}{l}\text { Wave } \\
\text { I-V IPL }\end{array}$ & 42 & 4.95 & 0.28 & 19 & 4.7 & 0.28 & 3.22 & 0.0027 \\
\hline
\end{tabular}

Table 3: Comparison of absolute latencies and IPLs of 6 week old infants at the highest intensity level of this study with results of previous studies.

* SDs were assumed to be similar for both studies, hence SDs of Ileperuma et al (2015) were applied when calculating $t$ and $p$ values of Zimmerman et al's study'. 
Mean absolute latency values of wave I, III, V and I-III, III-V, I-V IPL values for the 3 month old children were not significantly different $(\mathrm{p}>0.05)$ from those reported by Jiang et $a l^{10}$ while mean absolute latency values of wave I, III and V for 3 month old children were significantly different $(\mathrm{p}<$ 0.05 ) from those reported by Zimmerman et $a l^{9}$ (Table 4).

\begin{tabular}{|c|c|c|c|c|c|c|c|c|c|c|c|c|c|}
\hline \multirow[t]{2}{*}{$\begin{array}{l}\text { ABR } \\
\text { measure }\end{array}$} & \multicolumn{3}{|c|}{$\begin{array}{l}\text { Ileperuma et al. } \\
\text { (2015) }\end{array}$} & \multicolumn{3}{|c|}{ Jiang et al. (1991) } & \multirow[t]{2}{*}{$\begin{array}{c}\mathrm{t} \\
\text { value }^{1}\end{array}$} & \multirow[t]{2}{*}{$\begin{array}{c}\mathrm{p} \\
\text { value }^{2}\end{array}$} & \multicolumn{3}{|c|}{$\begin{array}{c}\text { Zimmerman et al. } \\
\text { (1987) }\end{array}$} & \multirow[t]{2}{*}{ value $^{3}$} & \multirow[t]{2}{*}{$\begin{array}{l}\mathrm{p} \\
\text { value }^{4}\end{array}$} \\
\hline & $\mathrm{N}$ & $\begin{array}{c}\text { Mean } \\
(\mathrm{ms})\end{array}$ & $\mathrm{SD}$ & $\mathrm{n}$ & $\begin{array}{l}\text { Mean } \\
(\mathrm{ms})\end{array}$ & SD & & & $\mathrm{n}$ & $\begin{array}{c}\text { Mean } \\
(\mathrm{ms})\end{array}$ & SD & & \\
\hline $\begin{array}{l}\text { Wave I } \\
\text { absolute } \\
\text { latency }\end{array}$ & 42 & 1.90 & 0.26 & 15 & 1.9 & 0.16 & 0 & 0.99 & 19 & 1.73 & 0.16 & 3.12 & 0.0029 \\
\hline $\begin{array}{l}\text { Wave III } \\
\text { absolute } \\
\text { latency }\end{array}$ & 43 & 4.58 & 0.28 & 15 & 4.67 & 0.19 & -1.38 & 0.17 & 19 & 4.28 & 0.25 & 4.19 & 0.0002 \\
\hline $\begin{array}{l}\text { Wave V } \\
\text { absolute } \\
\text { latency }\end{array}$ & 43 & 6.66 & 0.28 & 15 & 6.66 & 0.21 & 0 & 0.99 & 18 & 6.26 & 0.25 & 5.49 & 0.0001 \\
\hline $\begin{array}{l}\text { Wave } \\
\text { I-III IPL }\end{array}$ & 42 & 2.64 & 0.33 & 15 & 2.77 & 0.17 & -1.93 & 0.05 & 19 & 2.55 & 0.33 & 0.98 & 0.33 \\
\hline $\begin{array}{l}\text { Wave III- } \\
\text { V IPL }\end{array}$ & 43 & 2.05 & 0.36 & 15 & 1.99 & 0.14 & 0.912 & 0.36 & 18 & 1.98 & 0.0 .3 & 0.70 & 0.48 \\
\hline $\begin{array}{l}\text { Wave } \\
\text { I-V IPL }\end{array}$ & 43 & 4.66 & 0.42 & 15 & 4.8 & 0.24 & -1.57 & 0.12 & 19 & 4.53 & 0.42 & 1.12 & 0.26 \\
\hline
\end{tabular}

Table 4: Comparison of absolute latencies and IPLs of 3-month old infants at the highest intensity level of this study with results of previous studies.

* SDs were assumed to be similar for both studies, hence SDs of Ileperuma et al. (2015) were applied when calculating $t$ and $\mathrm{p}$ values of Zimmermanet $a l^{[9]}$ 's study.

${ }^{1} t$ value comparing values between Ileperuma et al's study and Jiang et al. (1991)'s study

${ }^{2} \mathrm{p}$ value comparing values between Ileperuma et al's study and Jiang et al. (1991)'s study

${ }^{3} \mathrm{t}$ value comparing values between Ileperuma et al's study and Zimmerman et al. (1987)'s study

${ }^{4} \mathrm{p}$ value comparing values between Ileperuma et al's study and Zimmerman et al. (1987)'s study 
$\underline{6 \text { months }}$

There were no significant differences in any of the parameters considered between this study and those reported by Jiang et $a l^{10}$ (Table 5 ).

\begin{tabular}{|c|c|c|c|c|c|c|c|c|}
\hline \multirow{2}{*}{$\begin{array}{l}\mathrm{ABR} \\
\text { measure }\end{array}$} & \multicolumn{3}{|c|}{ Ileperuma (2015) } & \multicolumn{3}{|c|}{ Jiang et al. (1991) } & \multirow[t]{2}{*}{ t value ${ }^{1}$} & \multirow[t]{2}{*}{$p$ value $^{2}$} \\
\hline & $\mathrm{n}$ & $\begin{array}{c}\text { Mean } \\
(\mathrm{ms})\end{array}$ & SD & $\mathrm{n}$ & $\begin{array}{c}\text { Mean } \\
(\mathrm{ms})\end{array}$ & $\mathrm{SD}$ & & \\
\hline $\begin{array}{l}\text { Wave I } \\
\text { absolute } \\
\text { latency }\end{array}$ & 42 & 1.87 & 0.26 & 14 & 1.85 & 0.14 & 0.366 & 0.715 \\
\hline $\begin{array}{l}\text { Wave III } \\
\text { absolute } \\
\text { latency }\end{array}$ & 43 & 4.47 & 0.18 & 14 & 4.46 & 0.19 & 0.17 & 0.864 \\
\hline $\begin{array}{l}\text { Wave V } \\
\text { absolute } \\
\text { latency }\end{array}$ & 43 & 6.38 & 0.25 & 14 & 6.41 & 0.18 & -0.488 & 0.628 \\
\hline $\begin{array}{l}\text { Wave } \\
\text { I-III IPL }\end{array}$ & 43 & 2.59 & 0.25 & 14 & 2.62 & 0.14 & -0.561 & 0.577 \\
\hline $\begin{array}{l}\text { Wave III- } \\
\text { V IPL }\end{array}$ & 43 & 1.91 & 0.22 & 14 & 1.95 & 0.14 & 0.795 & 0.431 \\
\hline $\begin{array}{l}\text { Wave } \\
\text { I-V IPL }\end{array}$ & 43 & 4.56 & 0.22 & 14 & 4.56 & 0.12 & -1.29 & 0.203 \\
\hline
\end{tabular}

Table 5: Comparison of absolute latencies and IPLs of 6 month old infants at the highest intensity level of this study with results of previous studies.

The reasons for prolonged latencies could be attributed to the sensitivity of the ABR instruments, sedation Vs natural sleep and the use of headphones Vs insert earphones. Gorga et al and Zimmerman et $\mathrm{al}^{9}$ had used a Nicolet CA-1000 system to record ABRs. Issa \& Ross ${ }^{3}$ had used a Medelec Sensor Programmable Evoked Response system, while Khatoon et $a l^{2}$ had used the RMS EMG EP MARK II machine to record ABR. This study used a Biologic Navigator Pro instrument for ABR data collection. With the development of advanced technology in the newer instruments, the different sensitivities of instruments may explain the prolonged latencies observed in this study as compared to earlier studies.

In this study, ABR measures were collected while infants and babies were in natural sleep and no sedation was used for any subject. Children in Jiang et $a l^{10}$ 's study and Gorga et $a l^{4}$ 's study were sedated using chloral hydrate. Zimmerman et $\mathrm{al}^{9}$ did not sedate infants for ABR testing. Chloral hydrate reduces muscle artifacts and thereby enhances the morphology of the waveform. However, there is no evidence to suggest that sedation delays absolute latencies or IPLs. Hence, it is unlikely that that using sedation or not was a possible reason for observing delayed latencies in Sri Lankan children.Van Campenet al $^{11}$ compared ABR measures using ER-3A insert earphones and supra-aural earphones (headphones) in a group of normal hearing adults. They reported that ABR measures in response to click stimuli were slightly elevated in insert earphones relative to the headphones. A delay of 0.8 to $1.0 \mathrm{~ms}$ was seen in terms of absolute latencies when insert earphones were used. These delays were contributed to spectral and temporal differences among earphones.

This study used ER-3A insert earphones to deliver the acoustic signal to the ear while and Gorga et al had used Beyer DT48 circum-aural earphones. Jiang et $a l^{10}$ and Issa \& Ross ${ }^{3}$ had used TDH 39 earphones, and Khatoon et $a l^{2}$ had used an electrically shielded earphone. Hence, a possible reason for prolonged absolute and inter-peak latencies in this study may be due to ER-3A insert earphones being used to deliver the acoustic signal to the ear. 


\section{Conclusion}

Normative ABR data for Sri Lankan children under 5 years of age was significantly delayed compared to normative $\mathrm{ABR}$ data reported in previous studies. The possible reasons for the delays in latencies could be the use of insert earphones and the sensitivity of the ABR instruments used in the collection of ABR waves. The mean latency values for waves I, III, V and inter-peak latency values for I-III, III-V, I-V plus 2 standard deviations for each ABR measure may be employed as the upper limit cutoff values in the interpretation of ABR data across Audiology clinics in Sri Lanka provided identical parameters have been employed to obtain ABRs (technical parameters, use of insert earphones, using natural sleep instead of sedation).

\section{References}

1. Cox C, Hack M, Metz D. Brainstem-evoked response audiometry: normative data from the preterm infant. Audiology [Internet]. 1981;20(1):5364.https://doi.org/10.3109/00206098109072682. PMid:7213201

2. Khatoon M, Nighute S, Nighute S, Singh R, Singh R, Awari A. Maturation of brainstem auditory evoked potential from full term infants \& children to young adult. Int J Biomed Res [Internet]. 2013;3(12):439. https://doi.org/10.7439/ijbr.v3i12.585

3. Issa A, Ross HF. An improved procedure for assessing ABR latency in young subjects based on a new normative data set. Int J PediatrOtorhinolaryngol [Internet]. 1995;32(1):35-47. https://doi.org/10.1016/0165-5876(94)01110-J

4. Gorga MP, Kaminski JR, Beauchaine KL, Jesteadt W, Neely ST. Auditory brainstem responses from children three months to three years of age: normal patterns of response. II. J Speech Hear Res [Internet].1989;32(2):281-8.https://doi.org/10.1044/jshr.3202.281. PMid:2739379

5. Hung KL. Development of auditory brainstem evoked response in normal Chinese children. Zhonghua Min Guo Xiao Er Ke Yi Xue Hui Za Zhi. 1989;30(1):23-9.

6. Casali RL, Santos MFC dos. Auditory Brainstem Evoked Response: response patterns of fullterm and premature infants. Braz J Otorhinolaryngol. 2010;76(6):729-38.

7. Fichino SN, Lewis DR, Fávero ML. Electrophysiologic threshold study in air and bone conduction in children with 2 months or less age. Braz J Otorhinolaryngol [Internet]. 2007;73(2):251-6. https://doi.org/10.1016/S1808-8694(15)31074-0

8. Starr A, Amlie RN, Martin WH, Sanders S. Development of auditory function in newborn infants revealed by auditory brainstem potentials. Pediatrics [Internet]. 1977;60(6):831https://doi.org/10.1542/peds.60.6.831.PMid:600595

9. Zimmerman MC, Morgan DE, Dubno JR. Auditory brainstem evoked response characteristics in developing infants. Annals of OtolRhinolLaryngol. 1987; 96:291-8. https://doi.org/10.1177/000348948709600311. PMid:3605953

10. Jiang ZD, Zheng MS, Sun DK, Liu XY. Brainstem auditory evoked responses from birth to adulthood: normative data of latency and interval. Hear Res [Internet]. 1991;54(1):67-74. https://doi.org/10.1016/0378-5955(91)90137-X

11. Van Campen LE, Sammeth CA, Hall JW 3rd, Peek BF. Comparison of Etymotic insert and TDH supra-aural earphones in auditory brainstem response measurement. J Am AcadAudiol. 1992;3(5):315-23. 